Int. J. Electrochem. Sci., 13 (2018) 11250 - 11262

International Journal of

ELECTROCHEMICAL

SCIENCE

www.electrochemsci.org

\title{
Simultaneous Determination of Hydroquinone and Catechol using Carbon Glass Electrode Modified with Graphene Quantum Dots
}

\author{
Jing Tang ${ }^{1 *}$, Xiaoqing $\mathrm{Ma}^{1}$, Jing Liu ${ }^{1}$, Shengbiao Zheng ${ }^{1}$, Jianfei Wang ${ }^{2 *}$ \\ ${ }^{1}$ College of Chemistry and Material Engineering, Anhui Science and Technology University, 233100, \\ Fengyang, Anhui Province, China \\ ${ }^{2}$ College of Resource and Environment, Anhui Science and Technology University, 233100, \\ Fengyang, Anhui Province, China \\ *E-mail: zhengtang102@ 163.com (Tang Jing), wangjf@ahstu.edu.cn (Wang Jianfei)
}

doi: $10.20964 / 2018.11 .52$

Received: 6 July 2018 / Accepted: 29 August 2018 / Published: 1 October 2018

In this study, an electrochemical sensor for the simultaneous detection of hydroquinone (HQ) and catechol (CC) was fabricated on glassy carbon electrode (GCE) modified with graphene quantum dots (GQDs). The prepared GQDs were characterized by transmission electron microscope and fourier transform infrared spectroscopy. The GQDs/GCE, which prepared by electrodeposition method, and characterized by electrochemical impedance spectra, exhibited excellent electrochemical catalysis and conductive properties for HQ and CC. Owing to the high electroactive surface area, good electrocatalytic activity and low charge transfer resistance of GQDs, HQ and CC can be easily measured simultaneously for the large separation of oxidation peak potentials $(113 \mathrm{mV})$ and do not interfere with each other. Under the optimal experimental condition, the oxidation peak currents were linear to HQ/CC in the range from $0.5 \mu \mathrm{M}$ to $100 \mu \mathrm{M}$ with the same low detection limits of $0.08 \mu \mathrm{M}(\mathrm{S} / \mathrm{N}=3)$. Simultaneous determination of HQ and CC with such electrode was conducted in river water samples with reliable recovery between $97.90 \%$ and $103.9 \%$.

Keywords: graphene quantum dots; hydroquinone; catechol; simultaneous; modified electrode

\section{$\underline{\text { FULL TEXT }}$}

(C) 2018 The Authors. Published by ESG (www.electrochemsci.org). This article is an open access article distributed under the terms and conditions of the Creative Commons Attribution license (http://creativecommons.org/licenses/by/4.0/). 